\title{
Management of a pregnant patient with chylomicronemia from a novel mutation in GPIHBP1: a case report
}

\author{
Min-Huan Lin ${ }^{\dagger}$, Xiao-Hui Tian ${ }^{\dagger}$, Xiu-Lan Hao, Hui Fei, Jian-Lan Yin, Dan-Dan Yan and Tian Li ${ }^{*} \mathbb{D}$
}

\begin{abstract}
Background: Familial chylomicronemia syndrome (FCS) is a rare autosomal recessive lipid disorder often associated with recurrent episodes of pancreatitis. It is documented in most cases with FCS due to the mutations of key proteins in lipolysis, including LPL, APOC2, APOA5, LMF1 and GPIHBP1.

Case presentation: We report the successful management of a 35-year-old pregnant woman carrying a novel homozygous frameshift mutation c.48_49insGCGG (p.P17A fs*22) in the GPIHBP1 gene with previous severe episodes of acute pancreatitis triggered by pregnancy, resulting in adverse obstetrical outcomes. With careful monitoring, the patient underwent an uneventful pregnancy and delivered a baby with no anomalies.

Conclusions: The case report contributes to the understanding of GPIHBP1-deficient familial chylomicronemia syndrome (FCS) and highlights gestational management of FCS patient.
\end{abstract}

Keywords: GPIHBP1, Chylomicronemia, Hypertriglyceridemia, Pancreatitis, Pregnancy

\section{Background}

Familial chylomicronemia syndrome (FCS), namely type 1 hyperlipoproteinemia according to Frederickson classification, is a rare disease with an incidence of about $1 /$ 1000,000 [1], yet is often complicated by recurrent and potentially fatal pancreatitis. The hallmark of FCS is abundant accumulations of chylomicrons in the circulation, lipemic appearance of patients' serum, fasting triglyceride levels exceeding $1000 \mathrm{mg} / \mathrm{dl}(11.2 \mathrm{mmol} / \mathrm{L})$ [2]. Typical manifestations of chylomicronemia include failure to thrive in infancy, recurrent pancreatitis in adolescence or adulthood, and physical examination and imaging may reveal hepatomegaly, splenomegaly, lipemia retinalis, cutaneous or visceral xanthomas, or coronary artery disease $(\mathrm{CAD})[3]$.

\footnotetext{
*Correspondence: litianlucky@126.com

${ }^{\dagger}$ Min-Huan Lin and Xiao-Hui Tian contributed equally to this work. Department of Obstetrics \& Gynecology, the Seventh Affiliated Hospital of Sun Yat-Sen University, 628 Zhenyuan Road, Guangming District, Shenzhen, China
}

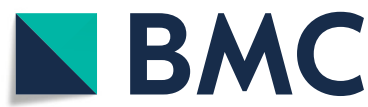

(c) The Author(s). 2020 Open Access This article is licensed under a Creative Commons Attribution 4.0 International License, which permits use, sharing, adaptation, distribution and reproduction in any medium or format, as long as you give appropriate credit to the original author(s) and the source, provide a link to the Creative Commons licence, and indicate if changes were made. The images or other third party material in this article are included in the article's Creative Commons licence, unless indicated otherwise in a credit line to the material. If material is not included in the article's Creative Commons licence and your intended use is not permitted by statutory regulation or exceeds the permitted use, you will need to obtain permission directly from the copyright holder. To view a copy of this licence, visit http://creativecommons.org/licenses/by/4.0/ The Creative Commons Public Domain Dedication waiver (http://creativecommons.org/publicdomain/zero/1.0/) applies to the data made available in this article, unless otherwise stated in a credit line to the data.
So far as studies have revealed, FCS is often caused by homozygous mutations of some pivotal genes encoding key proteins in lipolysis, including $L P L$ in the majority, as well as $A P O C 2, A P O A 5, L M F 1$ and GPIHBP1 [4]. In contrast with FCS, acquired chylomicronemia is caused by LPL or GPIHBP1 autoantibodies [5]. GPIHBP1 was first identified in 2003 [6] and has been gradually recognized to play a critical role in lipolysis since 2007 [7]. There has been some published literature proving the lipolytic mechanism of GPIHBP1 and case reports of GPIHBP1 mutations as well, but knowledge about GPIHBP1-deficient disease is still limited. We report a FCS patient, who had mild hypertriglyceridemia but recurrently exacerbated by pregnancy, causing severe pancreatitis that resulted in adverse obstetrical outcomes, one fetal demise and one child with cerebral palsy. Genetic sequencing reveals a homozygous frame-shift mutation of GPIHBP1, p.P17A fs*22. We also discussed the mutations in GPIHBP1, the influence of FCS towards pregnancy and the management in pregnant patient. 


\section{Case presentation}

A 35 year-old patient, gravida 4 para 1 , was seen in our clinic at 9 weeks' gestation age with a history of recurrent pancreatitis. Splenomegaly was found on routine physical examination when the patient was 23 years old. The initial attack of pancreatitis resulted in fetal demise at 22 weeks of her first pregnancy 7 years ago. The next attack occurred during her second pregnancy 4 years ago presented at 26 weeks' gestation, after treatment it subsided gradually. The following third attack occurred at 35 weeks complicated by multiple organ failure, an emergency cesarean section was conducted and a female neonate delivered with severe asphyxia, later was diagnosed with cerebral palsy. The patient's platelet count fell to $40 \times 10^{9} / \mathrm{L}$ during the second pregnancy, with the level of $70-80 \times 10^{9} / \mathrm{L}$ at postpartum. The fourth pancreatitis attack occurred 2 years ago was mild. The patient had no history of gallstones, alcohol use, diabetes mellitus or medication use. The parents and two siblings of the patient were all healthy, with no known consanguinity marriage in the family.

At her first visit to our clinic at 9 weeks' gestation, the fact that all the episodes of pancreatitis were triggered by taking fatty food was noted; the suspicious hyperlipidemic pancreatitis was diagnosed although without the laboratory test. The patient's weight was $47 \mathrm{~kg}$, height was $160 \mathrm{~cm}$, and body mass index (BMI) was $18.4 \mathrm{~kg} / \mathrm{m}^{2}$ before pregnancy. No xanthomas or lipemia retinalis was found. Abdominal ultrasound revealed splenomegaly but no hepatomegaly. The plasma triglyceride level was $2.64 \mathrm{mmol} / \mathrm{L}$, a high-density lipoprotein cholesterol level $0.70 \mathrm{mmol} / \mathrm{L}$ and a cholesterol level $2.58 \mathrm{mmol} / \mathrm{L}$. She was recommended a low-fat diet. Plasma lipid levels were monitored monthly, later bimonthly, and showed a gradual increase of triglyceride and cholesterol levels. At 18 weeks' gestation, when the plasma triglyceride level was 13.91 $\mathrm{mmol} / \mathrm{L}$ and cholesterol $6.75 \mathrm{mmol} / \mathrm{L}$, fenofibrate $(200 \mathrm{mg}$ once daily) was started to reduce the triglyceride level and decrease the risk of pancreatitis, with minimal effect.

At 25 weeks, the patient was admitted to the obstetrical ward with a plasma triglyceride level of 17.09 $\mathrm{mmol} / \mathrm{L}$ and a cholesterol level of $7.53 \mathrm{mmol} / \mathrm{L}$ (triglyceride levels throughout the pregnancy shown in Fig. 1). A multidisciplinary team consisting of obstetricians, dieticians, general surgeons and internal medicine specialists was involved. Combining the patient's history of recurrent pancreatitis and blood test results, chylomicronemia was diagnosed. A low-fat diet was provided to the patient with $11 \%$ of total calories from fat per day since admission, dieticians formulated detailed diet plans including specific food of specific weight and the cooking method was water-boiling without cooking oil; besides fenofibrate $200 \mathrm{mg}$ once daily, she was placed on ezetimibe $10 \mathrm{mg}$ once daily and a pregnancy-supplement tablet once daily (containing $200 \mathrm{mg}$ docosahexaenoic acid and $80 \mathrm{mg}$ eicosapentaenoic acid). Although omega-3 fatty acids were recommended by the American Association of Clinical Endocrinologists (AACE) to lower triglyceride [8], it was not administered to our patient due to a lack of approval in China. Magnetic resonance of the pancreas showed no signs of post-pancreatitis complications. With dietary adjustment later on with only $4 \%$ of calories from fat per day, plasma triglyceride levels

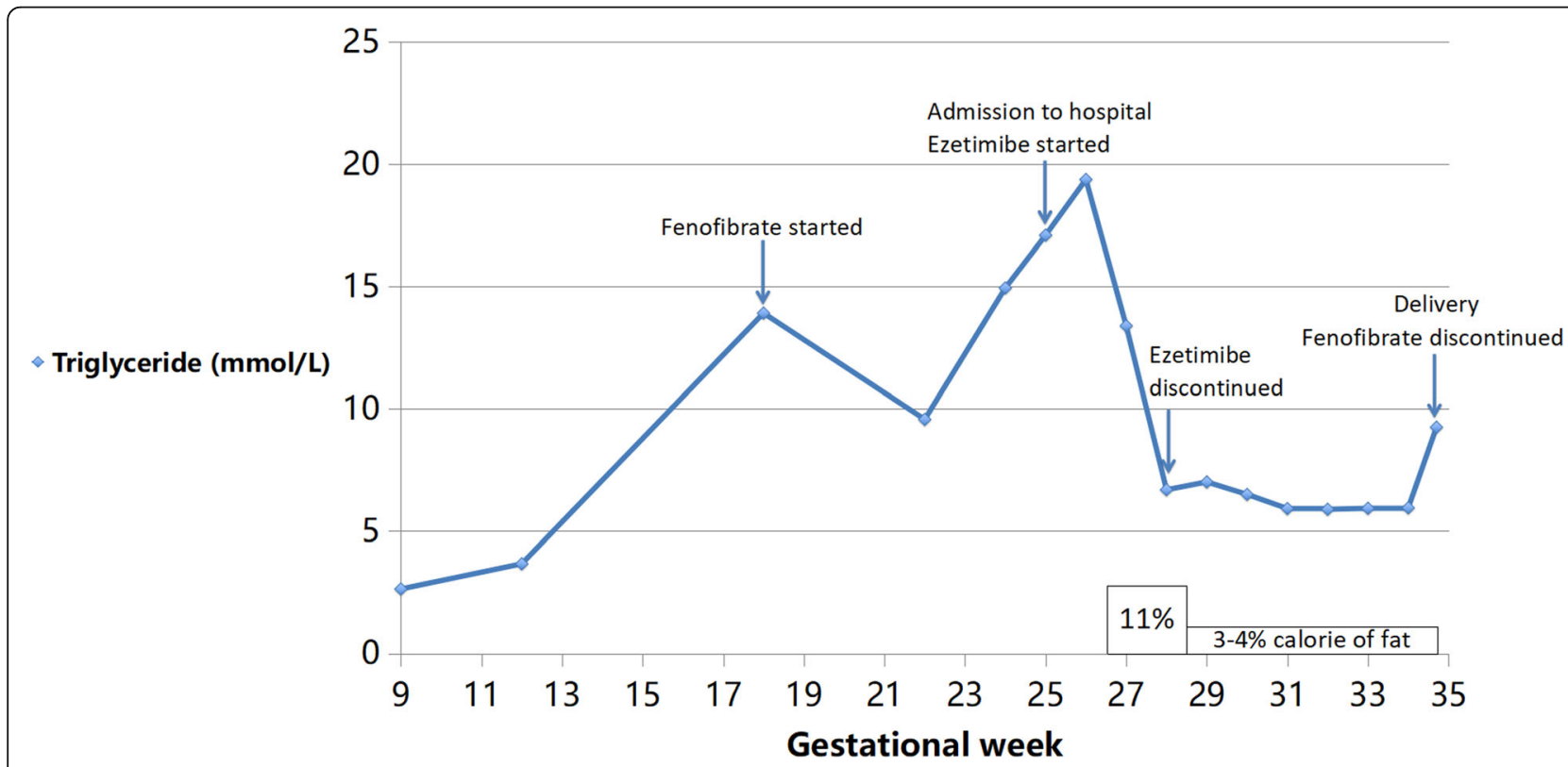

Fig. 1 Triglyceride levels (shown as points connected by a line), percentage of dietary fat of total calories (shown as bars) and management of the patients at different gestational weeks 
were slowly decreasing and ezetimibe was discontinued at $27^{5 / 7}$ weeks. Since 31 weeks' gestation, the plasma triglyceride level was maintained between $5.64-5.98 \mathrm{mmol} /$ $\mathrm{L}$ but could not be lowered any further. Monthly ultrasound showed normal growth of the fetus (fetal growth curve [9] shown in Fig. 2) and daily non-stress tests from 32 weeks did not yield abnormal results.

Taking into account the adverse pregnancy outcome of the patient and the knowledge of some acute pancreatitis occurrence with plasma triglyceride levels between $5.65 \mathrm{mmol} / \mathrm{L}$ to $11.3 \mathrm{mmol} / \mathrm{L}$ [10], it was recommended to perform cesarean delivery at $34^{5 / 7}$ weeks. A single course of corticosteroids was administered $48 \mathrm{~h}$ before the operation. On the surgery day, plasma triglyceride increased to $8.02 \mathrm{mmol} / \mathrm{L}$, indicating the influence of dexamethasone toward triglyceride metabolism. A healthy male neonate weighing $2500 \mathrm{~g}$ was born, with Apgar scores of 9 and 9 at 1 and $5 \mathrm{~min}$, respectively. Fenofibrate was discontinued post-partum, and she was discharged 8 days postpartum (plasma triglyceride level $6.06 \mathrm{mmol} / \mathrm{L}$, body weight $58 \mathrm{~kg}$ ). Keeping a low-fat diet with $6 \%$ calories from fat, until the latest follow-up (one hundred days postpartum), the patient's plasma triglyceride at no time exceeded $10 \mathrm{mmol} / \mathrm{L}$.

The neonate was admitted to Neonatal Intensive Care Unit (NICU) due to prematurity and was soon administered intravenously with lipid emulsion to correct the essential fatty acid deficiency. Although he suffered from recurrent apnea that required continuous positive airway pressure (CPAP) for 3 days, the neonate recovered well and was discharged on day 22 . For the first one hundred days, the infant showed normal development physically.

Whole blood samples of the patient were sent to Beijing Genomics Institute-Shenzhen. The genomic DNA was extracted following standard protocols. The 3583 target genes for whole exome sequencing were based on Mendelian disease-causing variants from OMIM database (updated Jan 11th, 2016). Using the method of target capture and next-generation sequencing, the exons with intron-exon boundaries of target genes were sequenced in a BGISEQ-500 sequencer (MGI, Shenzhen). A total of $17,129.07 \mathrm{Mb}$ of sequence data were produced with an average depth of coverage of 99.76 times and $95.89 \%$ of the total bases covered at 30 times. The result reveals a homozygous GPIHBP1 frame-shift mutation c.48_49insGCGG (p.P17A fs*22), which was absent from the ExAC database. The insertion of 4 nucleotides at the codon 17 in the signal peptide domain of GPIHBP1 leads to the introduction of the stop codon at the position 22 , probably producing a truncated and nonfunctional protein. Combining results from the prediction tools Condel [11], PolyPhen2 and SIFT, this mutation is considered likely pathogenic according to the guidelines of the American College of Medical Genetics and Genomics.

\section{Discussion and conclusions}

We describe a patient with GPIHBP1-deficient FCS who had had adverse pregnancy outcomes due to severe pancreatitis. A stringent low-fat diet and oral fenofibrate were able to decrease triglyceride at a relatively safe level. In addition, we closely monitor the patient's liver enzyme, creatine kinase, blood glucose and fetus NST and growth. Although in our case ezetimibe was advised by the internal medicine specialist to lower cholesterol, it wasn't recommended in FCS cases in literature. Given the adverse pregnancy outcome of the patient and the risk of pancreatitis, we delivered the baby at $34^{5 / 7}$ weeks through cesarean section. Though corticosteroids was administered for fetal maturation, it did trigger synthesis of triglyceride and might have the risk of triggering pancreatitis, reminding us to cautiously use corticosteroids on FCS patients. In all, the pregnancy outcome is favorable.

Of note, FCS is characterized by accumulations of chylomicrons in the circulation. The synthesis of chylomicrons is the first step of the exogenous triglyceride lipolytic process [12]. Triglyceride-rich lipoproteins (TRLs), constituted by chylomicrons and very lowdensity lipoproteins (VLDLs), are processed by lipoprotein lipase (LPL) with other cofactors including glycosylphosphatidylinositol-anchored high density lipoprotein-binding protein 1 (GPIHBP1) [13]. GPIHBP1 is a glycosylphosphatidylinositol-anchored glycoprotein

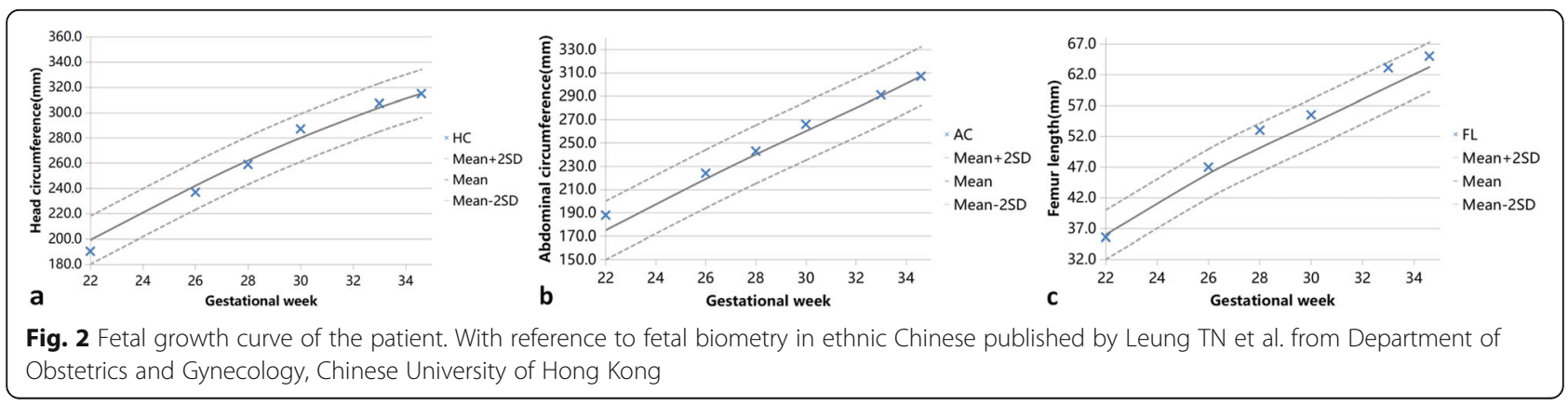


of the Lymphocyte Antigen 6 (Ly6) family specifically generated in capillary endothelial cell [13].There are four exons of the GPIHBP1 encoding four key features, including an amino-terminal signal peptide, an acidic domain, a three-fingered LU (Ly6-uPAR/lymphocyte antigen 6-urokinase-type plasminogen activator receptor) domain and a signal sequence [14]. After modification of GPIHBP1, it is trafficked to both the basolateral and apical surface of endothelial cells [12], mainly in skeletal muscle, heart and adipose tissue, being virtually absent in the brain [7]. GPIHBP1 actively transports LPL from interstitial space to capillary lumen and the GPIHBP1-LPL binding "attenuates the unfolding of LPL's catalytic domain" [14], thus prompting LPL to process TRLs in the capillary. With deficient GPIHBP1 gene, including homozygous or compound heterozygous missense mutations, GPIHBP1 is polymerized and chylomicrons accumulate in the circulation, causing FCS [15]. Plus, mutations in LPL, APOC2, APOA5 and LMF1 genes cause FCS as well, while LPL or GPIHBP1 autoantibodies lead to acquired chylomicronemia [5]. Strangely enough, $L p l$-kicked out mice died shortly after birth with plasma triglyceride levels as high as 20,000 $\mathrm{mg} / \mathrm{dl}$ [16], whereas Gpihbp1-kicked out mice survived and had far lower triglyceride levels (plasma triglyceride levels of adult mice $1000-5000 \mathrm{mg} / \mathrm{dl}$, pup mice $120 \pm 12$ $\mathrm{mg} / \mathrm{dl}$ ) [7]. Such phenotypic differences from LPLdeficient cases were allegedly attributed to "the fenestrated capillaries of the liver which allow access of TRLs to LPL" [14] even without properly functioning GPIHBP1.

FCS has come to be recognized as one of the leading factors of acute pancreatitis in pregnancy. There is physiologic hypertriglyceridemia occurring during the last two-thirds of gestation due to the progressive climb of plasma estrogen levels and the insulin-resistant condition, both enhancing VLDL production and decreasing LPL expressions and activities in the liver [17]. In uncomplicated pregnancies, by the third trimester, plasma triglyceride levels rise between 2- and 4-fold, with a mean of $79 \mathrm{mg} / \mathrm{dL}, 151 \mathrm{mg} / \mathrm{dL}$ and $245 \mathrm{mg} / \mathrm{dL}$ in the first, second and third trimester respectively [18]. In severe hypertriglyceridemia especially in FCS cases, large amounts of triglycerides in the pancreas are hydrolyzed by pancreatic lipase, producing a vast number of free fatty acids (FFA), which causes injury to the pancreatic acinar cells and capillaries. In such an acid environment, pancreatic local ischemia and activation of trypsinogen by FFA trigger acute pancreatitis (Havel et al., 1969) [19].

Well-recognized guidelines of FCS in the nonpregnant state have been published $[2,8,20]$, but few for the pregnant population [21]. Based on our experience with this patient and literature studies, for pregnant women with or without FCS, baseline lipid profiles should be evaluated at early pregnancy for better supervision during pregnancy. For patients with chylomicronemia, a nuanced approach should be developed to balance between maternal triglyceride control and fetal needs. A strict low-fat diet formulated by a dietician is the mainstay therapy of FCS. Theoretically, seeing that chylomicrons are produced exogenously [12], a strictly formulated low-fat diet (less than 20\% of total calories from fat per day, or furthermore, less than $10 \%$ ) should be effective in reducing triglyceride levels [21]. Intriguingly, the risk of macrosomia and large for gestational age (LGA) is positively correlated with maternal serum triglyceride levels [22]. In our case, even with low-fat diet, fetal growth was appropriate for the gestational age. To avoid essential fatty acid deficiency, omega-3-acid ethyl esters and medium-chain triglycerides (MCT) are also recommended as additional nutritional support $[8$, 23]. If a patient's not compliant to the diet or triglyceride levels are refractory to control, hospitalization should be considered for better diet supervision [24]. Fibrates have been reported in quite some studies to effectively control triglyceride levels without fetal malformation or infant development [24, 25]. Fasting, parenteral nutritional support, insulin infusion are routinely needed with pancreatitis, or in some cases without pancreatitis [26]. Plasmapheresis is proven effective in refractory cases $[27,28]$. If early induction of labor or preterm C-section is required in intractable situations, obstetricians should be prudent to prescribe dexamethasone for use of fetal maturation, since dexamethasone might trigger pronounced triglyceride increase or pancreatitis.

In conclusion, this case report contributes to the understanding of GPIHBP1-deficient familial chylomicronemia syndrome (FCS). We should be aware of potential dyslipidemia in pregnant women even without a family history. We also highlight lipid evaluation at early pregnancy, diet formula and gestational management for patients with FCS.

\section{Abbreviations \\ FCS: Familial chylomicronemia syndrome; CAD: Coronary artery disease: BMl: Body mass index; AACE: American Association of Clinical Endocrinologists; NICU: Neonatal Intensive Care Unit; CPAP: Continuous positive airway pressure; TRLs: Triglyceride-rich lipoproteins; VLDLs: Very low- density lipoproteins; LPL: Lipoprotein lipase; \\ GPIHBP1: Glycosylphosphatidylinositol-anchored high density lipoprotein- binding protein 1; Ly6: Lymphocyte Antigen 6; LU: Ly6-uPAR/lymphocyte antigen 6-urokinase-type plasminogen activator receptor; FFA: Free fatty acids; LGA: Large for gestational age; MCT: Medium-chain triglycerides}

\section{Acknowledgements}

We would like to thank our coworkers from departments of nutrition, general surgery and internal medicine for their valuable advice on the patient's treatment.

\section{Authors' contributions}

$\mathrm{MHL}$ and XHT drafted the manuscript; XLH and HF organized the patient data; JLY and DDY drew the diagrams; TL revised the manuscript; all authors read and approved the final manuscript. 


\section{Funding}

No financial support was received for this article.

\section{Availability of data and materials}

The datasets analyzed during the current study are not publicly available due to protection of the patient's privacy but are available from the corresponding author on reasonable request.

\section{Ethics approval and consent to participate}

This study was approved by the Ethics Committee of the Seventh Affiliated Hospital of Sun Yat-Sen University, and written informed consent was obtained from the patient included in the study.

\section{Consent for publication}

Written informed consent for publication was obtained from the patient.

\section{Competing interests}

The authors declare that they have no competing interests.

Received: 14 January 2020 Accepted: 22 April 2020

Published online: 06 May 2020

\section{References}

1. Brahm AJ, Hegele RA. Chylomicronaemia--current diagnosis and future therapies. Nat Rev Endocrinol. 2015;11(6):352-62.

2. Falko JM. Familial chylomicronemia syndrome: a clinical guide for endocrinologists. Endocr Pract. 2018;24(8):756-63.

3. Miller M, Stone NJ, Ballantyne C, et al. Triglycerides and cardiovascular disease: a scientific statement from the American Heart Association. Circulation. 2011;123(20):2292-333.

4. Johansen CT, Hegele RA. Genetic bases of hypertriglyceridemic phenotypes. Curr Opin Lipidol. 2011;22(4):247-53.

5. Beigneux AP, Miyashita K, Ploug M, et al. Autoantibodies against GPIHBP1 as a cause of hypertriglyceridemia. N Engl J Med. 2017;376(17):1647-58.

6. loka RX, Kang MJ, Kamiyama S, et al. Expression cloning and characterization of a novel glycosylphosphatidylinositol-anchored high density lipoprotein-binding protein, GPI-HBP1. J Biol Chem. 2003;278(9): 7344-9.

7. Beigneux AP, Davies BS, Gin P, et al. Glycosylphosphatidylinositol-anchored high density lipoprotein-binding protein 1 plays a critical role in the lipolytic processing of chylomicrons. Cell Metab. 2007;5(4):279-91.

8. Jellinger PS, Handelsman Y, Rosenblit PD, et al. American Association of Clinical Endocrinologists and American College of endocrinology guidelines for management of dyslipidemia and prevention of cardiovascular disease. Endocr Pract. 2017;23(4):479-97.

9. Leung TN, Pang MW, Daljit SS, et al. Fetal biometry in ethnic Chinese: biparietal diameter, head circumference, abdominal circumference and femur length. Ultrasound Obstet Gynecol. 2008;31(3):321-7.

10. Kilinc F, Senates $E$, Demircan F, et al. Are there differences in the management of acute pancreatitis cases due to severe hypertriglyceridemia in pregnant women? Med Sci Monit. 2018;24:5619-23.

11. González-Pérez A, López-Bigas N. Improving the assessment of the outcome of nonsynonymous SNVs with a consensus deleteriousness score. Condel Am J Hum Genet. 2011;88(4):440-9

12. Ramasamy I. Recent advances in physiological lipoprotein metabolism. Clin Chem Lab Med. 2014;52(12):1695-727.

13. Young SG, Davies BS, Voss CV, et al. GPIHBP1, an endothelial cell transporter for lipoprotein lipase. J Lipid Res. 2011;52(11):1869-84.

14. Fong LG, Young SG, Beigneux AP, et al. GPIHBP1 and plasma triglyceride metabolism. Trends Endocrinol Metab. 2016;27(7):455-69.

15. Beigneux AP, Fong LG, Bensadoun A, et al. GPIHBP1 missense mutations often cause multimerization of GPIHBP1 and thereby prevent lipoprotein lipase binding. Circ Res. 2015;116(4):624-32.

16. Weinstock PH, Bisgaier CL, Aalto-Setälä K, et al. Severe hypertriglyceridemia, reduced high density lipoprotein, and neonatal death in lipoprotein lipase knockout mice. Mild hypertriglyceridemia with impaired very low density lipoprotein clearance in heterozygotes. J Clin Invest. 1995;96(6):2555-68.

17. Herrera E. Lipid metabolism in pregnancy and its consequences in the fetus and newborn. Endocrine. 2002;19(1):43-55.

18. Basaran A. Pregnancy-induced hyperlipoproteinemia: review of the literature. Reprod Sci. 2009;16(5):431-7.
19. Havel RJ. Pathogenesis, differentiation and management of hypertriglyceridemia. Adv Intern Med. 1968;15:117-54.

20. Berglund L, Brunzell JD, Goldberg AC, et al. Evaluation and treatment of hypertriglyceridemia: an Endocrine Society clinical practice guideline. J Clin Endocrinol Metab. 2012;97:2969-89.

21. Wong B, Ooi TC, Keely E. Severe gestational hypertriglyceridemia: a practical approach for clinicians. Obstet Med. 2015;8(4):158-67.

22. Wang X, Guan Q, Zhao J, et al. Association of maternal serum lipids at late gestation with the risk of neonatal macrosomia in women without diabetes mellitus. Lipids Health Dis. 2018;17(1):78.

23. Tsai EC, Brown JA, Veldee MY, et al. Potential of essential fatty acid deficiency with extremely low fat diet in lipoprotein lipase deficiency during pregnancy: a case report. BMC Pregnancy and Childbirth. 2004;4(1):27.

24. Goldberg AS, Hegele RA. Severe hypertriglyceridemia in pregnancy. J Clin Endocrinol and Metab. 2012;97(8):2589-96.

25. Whitten AE, Lorenz RP, Smith JM. Hyperlipidemia-associated pancreatitis in pregnancy managed with fenofibrate. Obstet Gynecol. 2012;117(2):517-9.

26. Yamamoto $\mathrm{H}$, Onishi $\mathrm{M}$, Miyamoto $\mathrm{N}$, et al. Novel combined GPIHBP1 mutations in a patient with hypertriglyceridemia associated with CAD. J Atheroscler and Thromb. 2013;20(10):777-84.

27. Michalova R, Mankova A, Vnucak M, et al. Therapeutic plasma exchange in secondary prevention of acute pancreatitis in pregnant patient with familial hyperchylomicronemia. Biomed Pap Med Fac Univ Palacky Olomouc Czech Repub. 2019;163(1):90-4.

28. Djelmis J, Ivanisevic M, Kosi N. Plasmapheresis in pregnant patient with familial hypertriglyceridemia. Eur J Obstet Gynecol Reprod Biol. 2016;201: $226-7$.

\section{Publisher's Note}

Springer Nature remains neutral with regard to jurisdictional claims in published maps and institutional affiliations.

Ready to submit your research? Choose BMC and benefit from:

- fast, convenient online submission

- thorough peer review by experienced researchers in your field

- rapid publication on acceptance

- support for research data, including large and complex data types

- gold Open Access which fosters wider collaboration and increased citations

- maximum visibility for your research: over $100 \mathrm{M}$ website views per year

At BMC, research is always in progress.

Learn more biomedcentral.com/submissions 